\title{
Elucidating Cooperative Luminescence and Cooperative Sensitisation Upconversion of Nonanuclear Lanthanide Complexes in Solution
}

\author{
Richard C. Knighton, ${ }^{* a] \dagger}$ Lohona K. Soro, ${ }^{[a] \dagger}$, Laura Francés-Soriano, ${ }^{[b]}$ Aurora Rodríguez-Rodríguez, ${ }^{[c]}$ \\ Guillaume Pilet, ${ }^{[\mathrm{d}]}$ Marc Lenertz, ${ }^{\left[{ }^{[e]}\right.}$ Carlos Platas-Iglesias, ${ }^{[c]}$ Niko Hildebrandt, ${ }^{[b],[f]}$ Loïc J. \\ Charbonnière*[a] \\ [a] Dr. R. C. Knighton, L. K. Soro, Dr. L. J. Charbonnière, Equipe de synthèse pour l'analyse (SynPA), Institut Pluridisciplaire Hubert Curien (IPHC), UMR \\ 7178, CNRS/Université de Strasbourg, ECPM, 25 rue Becquerel, 67087 Strasbourg cedex, France. \\ E-mail: knighton@unistra.fr, I.charbonn@unistra.fr \\ [b] Dr. L. Francés-Soriano, Prof. N. Hildebrandt, nanoFRET.com, Laboratoire COBRA (Chimie Organique, Bioorganique, Réactivite et Analyse), Université de \\ Rouen Normandie, CNRS, INSA, 76821 Mont Saint-Aignan, France. \\ [c] Dr. A. Rodríguez-Rodríguez, Dr. C. Platas-Iglesias, Centro de Investigacións Científicas Avanzadas (CICA) and Departamento de Química, Universidade \\ da Coruña, Campus da Zapateira-Rúa da Fraga 10, 15008 A Coruña, Spain. \\ [d] Dr. G. Pilet, Laboratoire des Multimatériaux et Interfaces (LMI) UMR 5615 CNRS, Université Claude Bernard Lyon 1, Avenue du 11 novembre 1918, 69622 \\ Villeurbanne cedex, France. \\ [e] Dr. M. Lenertz, Institut de Physique et Chimie des Matériaux de Strasbourg (IPCMS), UMR 7504, CNRS/Université de Strasbourg, 23 rue du Lœss, BP 43, \\ 67034 Strasbourg Cedex 2, France \\ [f] Prof. N. Hildebrandt, Université Paris-Saclay, 91190 Gif-sur-Yvette, France
}

\begin{abstract}
Upconversion nanoparticles have led to various breakthrough applications in solar energy conversion, imaging, and biomedicine. One key impediment is the facilitation of such processes at the molecular scale in solution where quenching effects are much more pronounced. In this work we explore, for the first time, molecular solution-state cooperative luminescence $(\mathrm{CL})$ upconversion arising from a $\mathrm{Yb}$ excited state and investigate the mechanistic origin behind cooperative sensitisation (CS) upconversion in $\mathrm{Yb} / \mathrm{Tb}$ systems. Counterintuitively, the best UC performances were obtained for $\mathrm{Yb} / \mathrm{Tb}$ ratios close to parity, resulting in the brightest molecular upconversion complexes with an unprecedented quantum yield of $2.8 \times 10^{-6}$ at a low laser power density of $2.86 \mathrm{~W} / \mathrm{cm}^{2}$.
\end{abstract}

\section{Introduction}

Upconverting phosphors - media which can generate high energy photons through the combination of two or more low energy photons - typically comprise of solid-state materials ${ }^{[1]}$ and nanoparticles (UCNPs). ${ }^{[2]}$ With wide application to in vivo imaging $)^{[3]}$ and as energy conversion materials. ${ }^{[4]}$ The key disadvantages in the case of bioconjugated imaging is that the relatively large UCNP size can induce deleterious effects on their biodistribution in biological media, an inability to cross the bloodbrain barrier, and suffer from reproducibility issues. ${ }^{[5]}$ Alternatively, molecularly upconverting biolabels would represent a panacea for these issues, allowing precise control of the size and composition of the UC material.

Molecular UC requires long-lifetime donor atoms to ensure that the first excited state persists for sufficient time to allow access to the higher lying excited state. At the molecular level, the main non-radiative quenching pathways involve vibronic deactivation through the overtones of the vibration absorption bands of the ligands or solvent molecules, ${ }^{[6]}$ with vibrations spanning from 1000 to $4000 \mathrm{~cm}^{-1}$ in the infrared region, while they rarely exceed $1600 \mathrm{~cm}^{-1}$ for phonons in solid lattices. ${ }^{[7]}$ Thus, the first and second overtones of some vibrations in metal complexes, typically encompassing $\mathrm{OH}, \mathrm{NH}$ and $\mathrm{CH}$ bonds, occur in the NIR domain and present excellent non-radiative deactivation pathways, reducing the excited state lifetime and the probability of UC. ${ }^{[8]}$ However, a few discrete coordination complexes have revealed their potential as UC molecular systems in the solidstate,,$^{[9]}$ and more rarely in diluted solutions. ${ }^{[10]}$ These rare examples are related to mechanisms of excited state absorption $(E S A)^{[10 a-c]}$, energy transfer UC $(E T U)^{[11]}$, cooperative sensitisation (CS), ${ }^{[10 \mathrm{~d}, 12]}$ or other mechanisms relevant to triplettriplet annihilation in organic dyes. ${ }^{[13]}$

A mandatory prerequisite to obtain a valuable UC signal is the spatial proximity of energy donors and acceptors at only few $\AA$ and Auzel noticed that, for CL in solids, the UC emission arises from localised 'ion clusters' that exhibit short intermetallic distances $(<5 \AA) \cdot{ }^{[14]}$ A strategy to achieve such properties at the molecular level can be found in the architectures of polynuclear complexes with high nuclearity, and multiple lanthanide ions at very close intermetallic distances. ${ }^{[12 b, 15]}$ Here we present an unprecedented $\mathrm{CL}$ phenomenon in a $\mathrm{Yb}_{9}$ complex and interrogation and optimization of the $\mathrm{Tb}$ centred $\mathrm{CS}$ in $\mathrm{Tb} / \mathrm{Yb}$ mixed complexes.

\section{Results and Discussion}

The nonanuclear complexes of the general composition $\left[\mathrm{Ln}_{9} \mathrm{~L}_{16}(\mathrm{OX})_{10}\right](\mathrm{OX})\left(\mathrm{L}=\right.$ Acac or Acac- $\mathrm{d}^{7}=$ acetylacetonate, $\mathrm{X}=\mathrm{H}$ or $\mathrm{D}$, yttrium ( $\mathrm{Y}$ ) will be integrated in the abbreviation of $\mathrm{Ln}$ for brevity) were prepared according to adaptation of literature procedure (Fig. 1a). ${ }^{[16]}$ The compounds were synthesised, varying the extent of deuteration by utilising hydrated or deuterated $\mathrm{Ln}$ salts, conducting the reaction in $\mathrm{CH}_{3} \mathrm{OH}$ or $\mathrm{CD}_{3} \mathrm{OD}$, and/or by using protiated or deuterated acetylacetone ${ }^{[17]}\left(X_{L n}, X_{S}\right.$, $X_{L}$ respectively; where $X=H$ or $D$; full synthetic details are available in the Electronic Supplementary Information). 


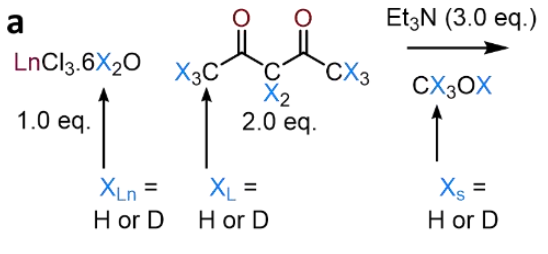

$\mathrm{Ln}=\mathrm{Y}, \mathrm{Yb}$,

$\mathrm{Yb}: \operatorname{Tb}(8: 1),(6: 3)$ or $(5: 4)$
$\left[\operatorname{Ln}_{9} \mathrm{~L}_{16}(\mathrm{OX})_{10}\right]^{+}(\mathrm{OX})^{-}$

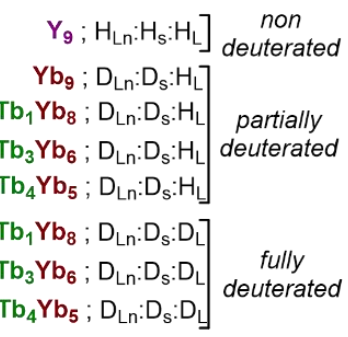

b

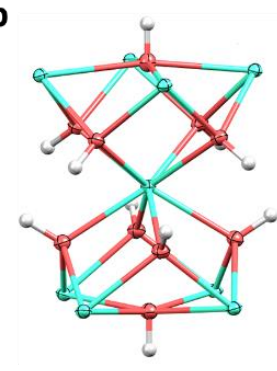

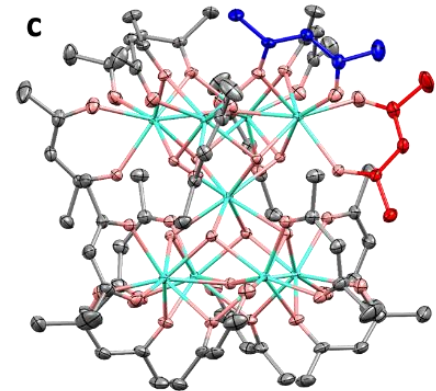

Figure 1. A) synthetic protocol for the preparation of the nonanuclear complexes. B) Single-crystal $X$-ray structure of $\left[T b_{4} Y b_{5} L_{16}(O D){ }_{10}\right](O D)\left(D_{L n}: D_{s}: H_{L}\right)$ representing the arrangement of the nine $\mathrm{Ln}$ (green), ten oxygen (red) and ten hydroxyl $\mathrm{H}$ atoms (white) core. C) Single-crystal $X-r_{1}$ ay structure of $\left[T b_{4} Y \mathrm{Yb}_{5} \mathrm{~L}_{16}(\mathrm{OD}){ }_{10}\right](\mathrm{OD})\left(\mathrm{D}_{\mathrm{Ln}}: \mathrm{D}_{\mathrm{s}}: \mathrm{H}_{\mathrm{L}}\right.$, ellipsoids plotted at the $50 \%$ probability level) representing the acac ligands in grey, with endo and exo acac positions pointed in red and blue respectively.

All isolated complexes were fully characterised by elemental analysis, infrared (IR) spectroscopy (Fig. S1-S7), ICP-AES analysis and powder X-ray diffraction (Fig. S8). In the case of the $\left[\mathrm{Tb}_{4} \mathrm{Yb}_{5} \mathrm{~L}_{16}(\mathrm{OD})_{10}\right](\mathrm{OD})$ complex the solid-state structure contains nine metal centres defining two square pyramids with shared apices at the central octacoordinated square anti-prismatic $(\theta \approx$ $45^{\circ}$ ) Ln(III) ion (Fig. 1b, Table S9). The coordination of the central ion is via eight $\mu_{3}-\mathrm{OH}$ ligands which bridge to the eight peripheral Ln(III) ions and cap the eight triangular faces of the pyramids. The remaining two upper and lower square faces are spanned by two $\mu_{4}-\mathrm{OH}$ bridges. The coordinative saturation of the peripheral $\mathrm{Ln}$ ions (Coordination Number $=8$ ) is provided by 16 bidentate acetylacetonate ligands present as endo and exo environments, shown in red and blue respectively (Fig. 1c). The eight endo bidentate ligands are bound to a single metal centre $\left(\mu_{1}\right)$ while the eight exo ligands display bridging between two metal centres $\left(\mu_{2}\right)^{[18]}$ The composition of the heteronuclear complexes was determined using ICP-AES and displayed a deviation of less than 0.26 integer units away from the theoretical compositions in all cases.
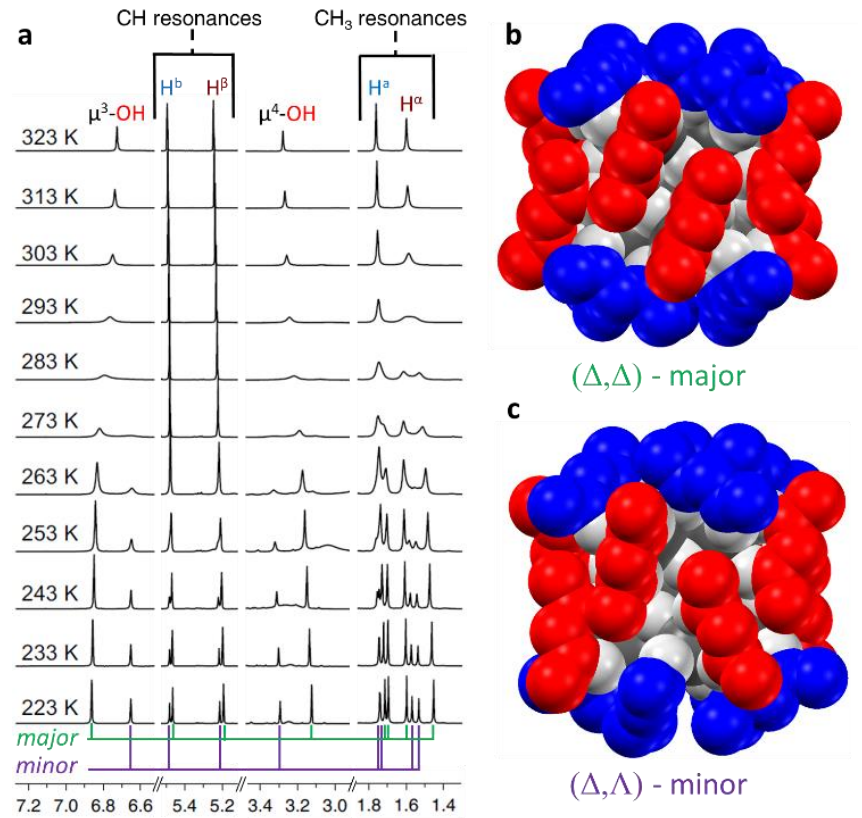

$(\Delta, \Lambda)$ - minor

The non-deuterated nonanuclear $\left[\mathrm{Y}_{9} \mathrm{~L}_{16}(\mathrm{OH})_{10}\right](\mathrm{OH})$ complex was prepared as a diamagnetic analogue of the $\mathrm{Ln}_{9}$ complexes to probe the structure in solution. The ${ }^{1} \mathrm{H}$ and ${ }^{13} \mathrm{C}$ NMR spectrum $\left(600 \mathrm{MHz}, 298 \mathrm{~K} \mathrm{CDCl}_{3}\right)$ shows time-averaged $C_{4}$ symmetry with two independent methyl and $\mathrm{CH}$ resonances, corresponding to endo and exo acetylacetonate ligands (Fig. 2a, S11). The appearance of equivalent methyl resonances in each Acac ligand reveals local $C_{2}$ symmetry due to fast ligand rotation on the NMR timescale. Two $\mathrm{OH}$ resonances were observable, corresponding to $\mu_{3}-\mathrm{OH}$ and $\mu_{4}-\mathrm{OH}$ environments. The ${ }^{1} \mathrm{H}$ and ${ }^{13} \mathrm{C}$ spectra of $\left[\mathrm{Y}_{9} \mathrm{~L}_{16}(\mathrm{OH})_{10}\right](\mathrm{OH})$ were recorded between $323 \mathrm{~K}$ and $223 \mathrm{~K}(600$ $\left.\mathrm{MHz}, \mathrm{CDCl}_{3}\right)$, The broad methyl resonance of the endo Acac $\left(\mathrm{H}^{\alpha}\right)$ reaches the slow-exchange regime first, displaying decoalescence around $298 \mathrm{~K}$, closely followed by the methyl resonance corresponding to exo acac $\left(\mathrm{H}^{\mathrm{a}}\right)$ at $273 \mathrm{~K}$, producing four methyl resonances. This indicates limitation of Acac rotation below $298 \mathrm{~K}$, corroborated by the absence of significant broadening of the $\mathrm{CH}$ Acac resonances $\left(\mathrm{H}^{\mathrm{b}}\right.$ and $\left.\mathrm{H}^{\beta}\right)$ at this temperature. Line shape analysis of the spectrum provides an estimation of the activation energy for the rotation of the Acac ligands about the local $C_{2}$ axis, which was found to be similar for the endo and exo ligands $\left(\Delta G^{\ddagger} 298=62.0 \pm 3.0 \mathrm{~kJ} \mathrm{~mol}^{-1}\right)$. Upon further cooling the four methyl environments further split into eight independent resonances with major $(\mathrm{M})$ and minor $(\mathrm{m})$ components, which was mirrored by all other resonances $\left(\mathrm{H}^{\mathrm{b}}, \mathrm{H}^{\beta}\right.$ $\mu_{3}-\mathrm{OH}$ and $\mu_{3}-\mathrm{OH}$ ) (Fig. 2a, S12) and the ${ }^{13} \mathrm{C}$ NMR spectrum (151 $\mathrm{MHz}, 233 \mathrm{~K}$, Fig. S13). Analysis using low-temperature correlation experiments permitted identification of four discrete Acac environments lacking local $C_{2}$ symmetry. These could be assigned (ROESY, HSQC, HMBC; 600 MHz, 223 K. Fig. S14-18) and the eight $\mathrm{CH}_{3}$ and eight $\underline{\mathrm{C}}=\mathrm{O}$ peaks correspond to two Acac ligands (endo and exo) in a major and minor set of isomers. The corresponding equilibrium constants $(K=[\mathrm{M}] /[\mathrm{m}])$ determined at different temperatures, were used to estimate the reaction enthalpy $\left(\Delta H^{\circ}\right)$ and reaction entropy $\left(\Delta S^{\circ}\right)$ for isomerisation reaction $\mathrm{m} \leftrightarrows \mathrm{M}$ (Table S19, Fig. S20-S21): $\Delta H^{\mathfrak{0}}=+5.0 \pm 0.9 \mathrm{~kJ}$ $\mathrm{mol}^{-1}$ and $\Delta S^{\circ}=+26.8 \pm 0.4 \mathrm{~kJ} \mathrm{~mol}^{-1}$. The full line shape analysis as well as attribution of the peaks in ${ }^{1} \mathrm{H}$ - and ${ }^{89} \mathrm{Y}$-NMR (Fig. S23S24) can be found in the supplementary information (Section S3).

Density functional theory (DFT) calculations were utilised to determine the identity of the two isomers observed by NMR. In order to understand the NMR observation of two exchanging diastereoisomers at low temperature, it is necessary to highlight the helical chirality of the compounds. The single-crystal X-ray structures of this family of clusters are isostructural. The presence of a $C_{4}$ axis passing through the central $\mathrm{Ln}$ atom and the two $\mu_{4^{-}}$ $\mathrm{OH}$ atoms induces a screwing orientation for the exo and endo ligands. Considering the isomer observed in the solid state (Fig. $\mathbf{2 b}$ ), the upper part of the complex viewed along the main axis displays a clockwise wrapping of the endo ligands $(\Delta)$ and an anti-

Figure 1. A) Truncated variable temperature ${ }^{1} \mathrm{H}$ NMR spectrum of $\left[\mathrm{Y}_{9} \mathrm{~L}_{16}(\mathrm{OH})_{10}\right](\mathrm{OH})\left(600 \mathrm{MHz}, 323-223 \mathrm{~K}, \mathrm{CDCl}_{3}\right)$. Red and blue respectively correspond to endo and exo acac ligands, $a$ and $\alpha$ to methyl groups, $b$ and $\beta$ to the methylene protons. B) and C) Energy minimised structures of respectively the $(\Delta, \Delta)$ and $(\Delta, \Lambda)$ isomers of $\left[Y_{9} L_{16}(\mathrm{OH})_{10}\right]$ (TPSSh/LanL2Dz level). 
clockwise $(\Lambda)$ one for the exo ones. The complexes crystallise with heterohelical chirality with respect to the upper and lower halves of the cluster, i.e. displaying $(\Lambda, \Delta)$ or $(\Delta, \Lambda)$, which are enantiomerically related and equiproportional in the solid state. We anticipated that one can also envisage diastereomerically related homohelical chiral enantiomers, i.e. $(\Delta, \Delta)$ or $(\Lambda, \Lambda)$ (Fig. 2 c) for which energy minimised structures (TPSSh/LanL2Dz level) were obtained for both sets of diastereomers. ${ }^{[19]}$ The calculated structure of $(\Delta, \Lambda)$ isomer contains a contra-rotatory ligand arrangement of the upper and lower $\operatorname{Ln}_{4}$ sections, while the $(\Delta, \Delta)$ isomer is characterised by pseudo-coplanar endo acetylacetonate ligands. The optimised structure of the $(\Delta, \Lambda)$ isomer presents virtually undistorted $S_{8}$ symmetry, while the $(\Delta, \Delta)$ isomer belongs to the $D_{4}$ point group. The main symmetry axis in both clusters contains the $\mu_{4}-\mathrm{OH}$ group and the central $\mathrm{Y}^{3+}$ ion. The calculated enthalpy difference between the two isomers favours the $(\Delta, \Lambda)$ isomer by $\Delta H^{\circ}=+7.5 \mathrm{~kJ} \mathrm{~mol}^{-1}$. However, a favourable entropy contribution results in a more negative Gibbs free energy for the $(\Delta, \Delta)$ isomer at $298 \mathrm{~K}\left(\Delta G^{\circ}{ }_{298}=-6.4 \mathrm{~kJ} \mathrm{~mol}^{-1}\right.$ for $\mathrm{m} \leftrightarrows \mathrm{M}$ ). These results are in good qualitative agreement with the increased prevalence of the major component at higher temperatures in the ${ }^{1} \mathrm{H}$ NMR spectra, and with the experimental values obtained $\left(\Delta H^{\circ}=+5.0 \mathrm{~kJ} \mathrm{~mol}^{-1} ; \Delta G^{\circ}{ }_{298}=-3.0 \mathrm{~kJ} \mathrm{~mol}^{-1}\right)$, assuming that the major isomer present in solution corresponds to the $(\Delta, \Delta)$ cluster. Further evidence was obtained from the ${ }^{89} Y$ NMR parameters calculated using relativistic DFT calculations showing excellent agreement between the observed and calculated chemical shifts (Supplementary Information, Section S4, Table 25, Fig. 26-29).

We isolated chosen nonanuclear complexes (listed in Table 1) to get more insight into their spectroscopic properties in $\mathrm{CD}_{3} \mathrm{OD}$. The first of the series was the reference compound composed of nine $\mathrm{Yb}$ atoms $\left(\mathrm{D}_{\mathrm{Ln}}, \mathrm{D}_{\mathrm{S}}, \mathrm{H}_{\mathrm{L}}\right)$. As for all other complexes (Fig. 3a, $\mathbf{3 b}$ ), the $\mathrm{Yb}_{9}$ complex in $\mathrm{CD}_{3} \mathrm{OD}$ displays a strong $\mathrm{S}_{0} \rightarrow \mathrm{S}_{1}$ absorption band in the UV region corresponding to the $S_{0} \rightarrow S_{1}$ transition of the Acac ligands $\left(\lambda_{\max }=289 \mathrm{~nm}, \varepsilon=19000 \mathrm{M}^{-1} \cdot \mathrm{cm}^{-1}\right)^{[20]}$ and $\mathrm{a} \mathrm{Yb}$ centred absorption band with maximum at $975 \mathrm{~nm}$, corresponding to the ${ }^{2} \mathrm{~F}_{5 / 2} \leftarrow{ }^{2} \mathrm{~F}_{7 / 2}$ transition ( $\lambda_{\max }=975 \mathrm{~nm}, \varepsilon=55 \mathrm{M}^{-1} . \mathrm{cm}^{-1}$, Fig. S30). Upon excitation in the ligand absorption band, the complex displays NIR emission associated with the ${ }^{2} \mathrm{~F}_{5 / 2} \rightarrow{ }^{2} \mathrm{~F}_{7 / 2}$ transition of $\mathrm{Yb}$ at $980 \mathrm{~nm}$, with an observed luminescence lifetime of $15 \mu \mathrm{s}$ and an overall luminescence quantum yield $\left(\varphi_{Y b}{ }^{L}\right)$ of $0.4 \%$. From the NIR absorption spectrum, the radiative luminescence lifetime of $\mathrm{Yb}$ was calculated according to the methodology of Werts and coworkers $^{[21]}$ to be $740 \mu \mathrm{s}$. The $\mathrm{Yb}$ centred quantum yield was calculated to be $2.1 \%$ using the equation:
The overall quantum yield being the product of the sensitisation efficiency from the ligand $\eta_{\text {sens }}$ times the metal centred quantum yield, a sensitisation efficiency of $20 \%$ was calculated. The most surprising spectroscopic information was observed when the $\mathrm{Yb}_{9}$ complex was excited by the laser at $980 \mathrm{~nm}$. A symmetric emission band, absent in pure $\mathrm{CD}_{3} \mathrm{OD}$, was then observed in the visible region with a maximum at ca. $503 \mathrm{~nm}$ which is attributed to cooperative luminescence from $\mathrm{Yb}$ clusters (Fig. $\mathbf{3 c}$ ).

Interestingly, while it has already been observed in $\mathrm{Yb} / \mathrm{Tb}$ doped solids, ${ }^{[25]}$ this is the first observation of this phenomenon in solution. To ascertain the origin of the upconversion signal, we recorded the conventional Log/Log plot representing the emission intensity as a function of the excitation power density (Fig. 3d) The linear fitting of the data afforded a slope of 1.8 , very close to the value of two expected for a two-photon process. In addition, the excited-state lifetime of the UC emitted signal was measured (Fig. S31) and determined to be $8 \mu \mathrm{s}$. For a cooperative luminescence process, this decay time should be related to that of $\mathrm{Yb},{ }^{[26]}$ following the reasoning that:

$$
\begin{gathered}
I_{Y b}(t)=I_{Y b}(0) \cdot \exp \left(-t / \tau_{Y b}\right) \text { and } I_{Y b 2}(t) \propto\left(I_{Y b}(t)\right)^{2}= \\
\left(I_{Y b}(0) \cdot \exp \left(-t / \tau_{Y b}\right)\right)^{2}=I_{Y b}(0)^{2} \cdot \exp \left(-2 t / \tau_{Y b}\right)
\end{gathered}
$$

i.e. the observed decay time of the cooperative luminescence should be half that of the $\mathrm{Yb},{ }^{[25 a]}$ in good agreement with the observation ( $8 \mu$ s for the CL UC and $15 \mu$ s for the $\mathrm{Yb}$ decay time).

Table 1 summarises the main spectroscopic properties of the isolated heteropolynuclear complexes. The UV-VIS-NIR absorption spectra of the isolated heterononanuclear complexes display a structureless band centred around $290 \mathrm{~nm}$ for all complexes. ${ }^{[20]}$ The NIR transitions $\left(\lambda_{a b s}=975 \mathrm{~nm}\right)$ are characteristic of the $\mathrm{Yb}$-centred ${ }^{2} \mathrm{~F}_{5 / 2} \leftarrow{ }^{2} \mathrm{~F}_{7 / 2}$ absorption, with the corresponding absorption coefficients $\left(\varepsilon_{Y b}=29-58 \mathrm{M}^{-1} \mathrm{~cm}^{-1}\right.$; $\mathrm{CD}_{3} \mathrm{OD}$ ) being broadly in line with the proportion of $\mathrm{Yb}$ in the clusters (Table 1).

Investigating the conventional Stokes downshifted photoluminescence properties of the complexes in $\mathrm{CD}_{3} \mathrm{OD}$, upon excitation into the Acac absorption band, two distinct emissive regions are evident in the visible and NIR domains (Fig. 3b, S32S35). These arise from both $\mathrm{Tb}\left({ }^{5} \mathrm{D}_{4} \rightarrow{ }^{7} \mathrm{~F} J\right.$ with $J=6$ to 3$)$ and $\mathrm{Yb}$ $\left({ }^{2} \mathrm{~F}_{5 / 2} \rightarrow{ }^{2} \mathrm{~F}_{7 / 2}\right)$ ions within the heteropolynuclear complexes. ${ }^{[27]}$ The emission of $\mathrm{Yb}$ can also be induced through direct excitation of $\mathrm{Tb}$ at $490 \mathrm{~nm}$ within the complexes, potentially indicating two competitive sensitisation pathways for $\mathrm{Yb}$ through the Acac $\mathrm{T}_{1}$ state and the $\mathrm{Tb}{ }^{5} \mathrm{D}_{4}$ energy levels, upon ligand irradiation.

$$
\emptyset_{Y b}=\tau_{o b s} / \tau_{\text {rad }}
$$

\begin{tabular}{|c|c|c|c|c|c|c|c|c|c|}
\hline ( & 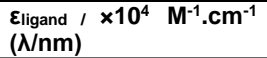 & $\varepsilon \mathrm{Yb} / \mathrm{M}^{-1} \cdot \mathrm{cm}^{-1}$ & $\begin{array}{l}\mathrm{TYb} \\
/ \mu \mathrm{s}^{\mathrm{a}}\end{array}$ & TradYb / $\mu \mathrm{S}$ & $\eta_{\text {sens }} / \%$ & $\mathrm{TTb} / \mu \mathrm{S}(\%)^{\mathrm{a}}$ & $\Phi_{Y b^{L b}}{ }^{L} \%$ & $\begin{array}{l}\Phi_{\mathrm{Tb}^{\mathrm{L}}}^{\mathrm{L}} \\
/ \%\end{array}$ & $\begin{array}{l}\Phi_{\text {uc }^{d}} /\left(\times 10^{-}\right. \\
{ }^{-}\end{array}$ \\
\hline $\begin{array}{l}\text { Ybs } \\
\left(D_{L n}: D_{S}: H_{L}\right)\end{array}$ & $19(289)$ & 58 & 15 & 742 & 20 & - & 0.4 & - & 0.003 \\
\hline $\mathrm{Tb}_{1} \mathrm{Yb}_{8}{ }^{27}\left(\mathrm{D}_{\mathrm{Ln}}: \mathrm{D}_{\mathrm{S}}: \mathrm{H}_{\mathrm{L}}\right)$ & 20 (291) & 49 & 17 & 683 & 23 & $\begin{array}{l}0.35(5 \%) \\
1.1(95 \%)\end{array}$ & $0.6^{\mathrm{e}}$ & $2.7^{e}$ & $0.1^{\dagger}$ \\
\hline $\mathrm{Tb}_{3} \mathrm{Yb}_{6}\left(\mathrm{D}_{\mathrm{Ln}}: \mathrm{Ds}_{\mathrm{s}}: \mathrm{H}_{\mathrm{L}}\right)$ & 20 (291) & 29 & 18 & 900 & 28 & $\begin{array}{l}0.34(11 \%) \\
1.0(89 \%)\end{array}$ & 0.5 & 4.1 & 0.3 \\
\hline $\begin{array}{l}T_{b_{4}} \mathrm{Yb}_{5} \\
\left(D_{L n}: D_{S}: H_{L}\right)\end{array}$ & 20 (292) & 24 & 20 & 817 & 10 & $\begin{array}{l}0.23(11 \%) \\
1.1(89 \%)\end{array}$ & 0.5 & 3.3 & 1.1 \\
\hline $\mathrm{Tb}_{3} \mathrm{Yb}_{6}\left(\mathrm{D}_{\mathrm{Ln}}: \mathrm{Ds}_{\mathrm{S}}: \mathrm{D}_{\mathrm{L}}\right)$ & $14(288)$ & 37 & 41 & 665 & 10 & $\begin{array}{c}0.21(6 \%) \\
0.90(94 \%)\end{array}$ & 0.6 & 3.9 & 1.9 \\
\hline $\begin{array}{l}\mathrm{Tb}_{4} \mathrm{Yb}_{5} \\
\left(\mathrm{D}_{\mathrm{Ln}}: \mathrm{D}_{\mathrm{S}}: \mathrm{D}_{\mathrm{L}}\right)\end{array}$ & $23(291)$ & 29 & 41 & 739 & 14 & $\begin{array}{l}0.15(6 \%) \\
0.9(94 \%)\end{array}$ & 0.8 & 2.9 & 2.8 \\
\hline
\end{tabular}

Table 1| Photophysical properties of the hetero-nonanuclear complexes obtained in $\mathrm{CD}_{3} \mathrm{OD}$ (unless otherwise stated).

a Excitation at $340 \mathrm{~nm}$. ${ }^{b}$ using cardiogreen (IR125) in $\mathrm{MeOH}(\Phi=0.078)$ as reference. ${ }^{[22]} \mathrm{c}$ Using Rhodamine6G in water $\left(\Phi=0.76 ; \lambda_{\text {exc }}=488 \mathrm{~nm}\right)$ as reference ${ }^{[23}$

${ }^{d}$ Excitation at $980 \mathrm{~nm}\left(P=2.86 \mathrm{~W} / \mathrm{cm}^{2}\right)$, compared to $\mathrm{Tb}_{1} \mathrm{Yb}_{8} \mathrm{D}_{\mathrm{Ln}}: \mathrm{D}_{\mathrm{S}}: \mathrm{H}_{\mathrm{L}}$ complex for the upconversion quantum yield. ${ }^{[12 b]}$ e $\mathrm{Values}$ obtained in MeOH. ${ }^{\dagger}$ Using $\left[\mathrm{Tb}(\mathrm{Glu}) \mathrm{H}_{2} \mathrm{O}\right] \mathrm{Na}$ in water $(\varphi=31.0 \%)$ for the UC quantum yield. ${ }^{[24]}$ 
a

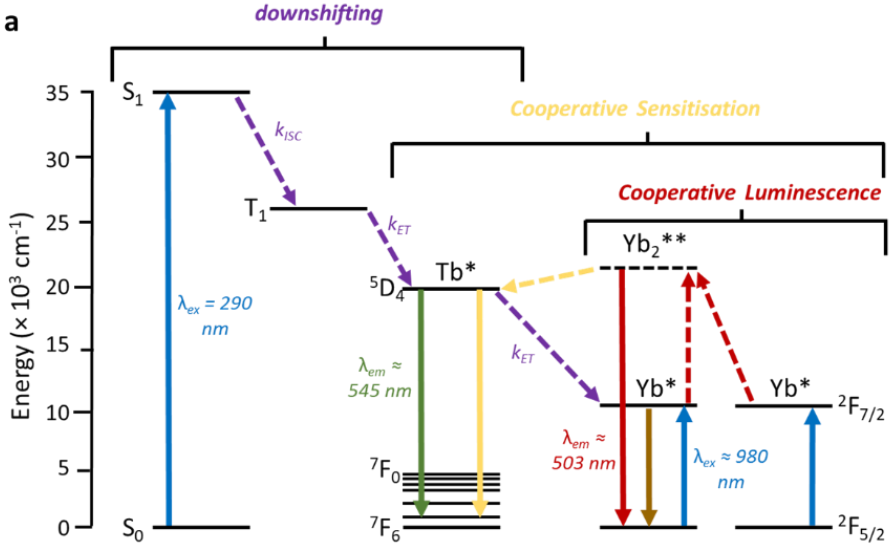

b

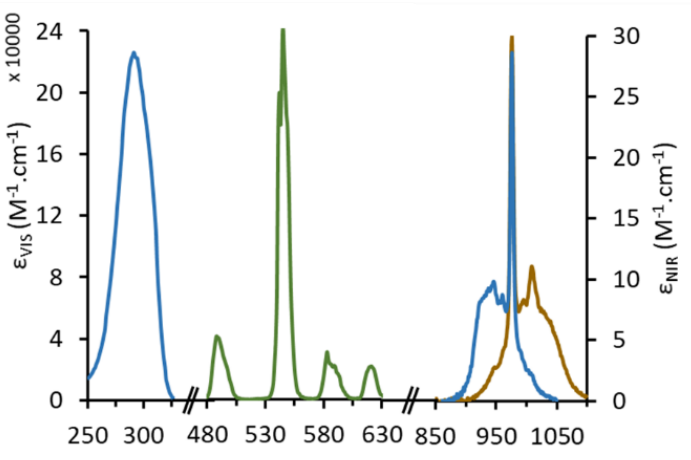

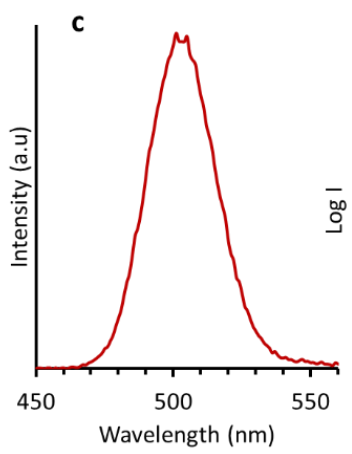

d

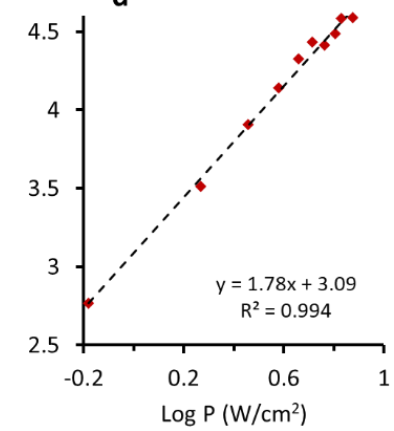

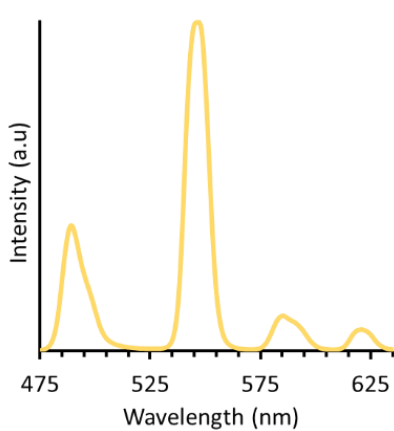

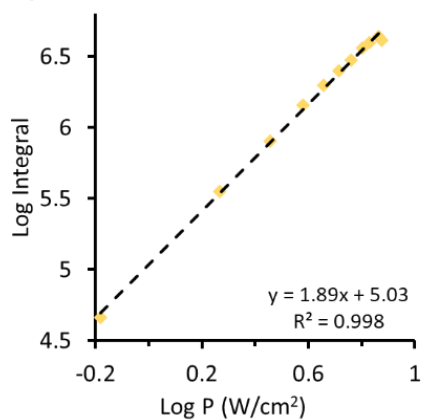

Figure 3 A) Schematic representation of the absorption (blue) downshifting (purple), cooperative luminescence (red) and cooperative sensitization (green) processes. B) main spectroscopic properties of the $\left[\mathrm{Tb}_{4} \mathrm{Yb}_{5}(\mathrm{acac})_{16}(\mathrm{OD})_{10}\right](\mathrm{OD})\left(\mathrm{D}_{\llcorner\mathrm{n}}: \mathrm{D}_{\mathrm{S}}: \mathrm{D}_{\llcorner}\right)$complex in $\mathrm{CD}_{3} \mathrm{OD}$ representing the absorption spectrum of the acac ligands in the UV (light blue) and of $\mathrm{Yb}$ in the NIR (dark blue), the Tb centred emission (green) and the Yb centred emission (orange) upon ligand excitation at 350 $\mathrm{nm}$ (for $\varepsilon$ values of the other complexes see Table 1). C) cooperative luminescence emission of the Ybg complex ( $\mathrm{D}_{\llcorner\mathrm{n}}: \mathrm{Ds}: \mathrm{H} \mathrm{L},[\mathrm{c}]=2.04 \mathrm{mM}, \mathrm{CD} 3 \mathrm{OD}, \lambda$ exc $=980$ $\mathrm{nm}, P=10.8 \mathrm{~W} / \mathrm{cm}^{2}$ ). D) UC intensity as a function of the incident pump power in a Log/Log scale. The black straight line represents the linear regression of the data. E) CL UC emission of the $\mathrm{Tb}_{4} \mathrm{Yb}_{5}$ complex ( $\left.\mathrm{D}_{\llcorner\mathrm{n}}: \mathrm{D}_{\mathrm{s}}: \mathrm{D}_{\llcorner},[\mathrm{c}]=1.4 \mathrm{mM}, \mathrm{CD}_{3} \mathrm{OD}, \lambda_{\text {exc }}=980 \mathrm{~nm}, P=2.86 \mathrm{~W} / \mathrm{cm}^{2}\right)$. F) CL UC intensity as a function of the incident pump power in a Log/Log scale.

With a non-deuterated ligand, the $\mathrm{D}_{\mathrm{Ln}}: \mathrm{D}_{\mathrm{S}}: \mathrm{H}_{\mathrm{L}}$ complexes display similar overall $\mathrm{Yb}$ quantum yields $\left(\Phi_{y b}{ }^{L}=0.5-0.6 \%\right)$ and lifetimes $\left(T_{Y b}=17-20 \mu \mathrm{s}\right)$, indicating a relatively small effect of substitution of $\mathrm{Yb}$ for $\mathrm{Tb}$. Contrastingly, the Tb quantum yield shows a small increase upon introduction of more $\mathrm{Tb}$ atoms, progressing from $2.7 \%$ in $\mathrm{Tb}_{1} \mathrm{Yb}_{8}$ to $3.3 \%$ in $\mathrm{Tb}_{4} \mathrm{Yb}_{5}$, arising from the decrease in non-radiative $\mathrm{Tb} \rightarrow \mathrm{Yb}$ energy transfer due to a lower local concentration of $\mathrm{Yb}$ acceptors. For the fully deuterated complexes, $D_{\llcorner n}: D_{S}: D_{\llcorner}$the salient observation is the dramatic increase of the longevity of the $\mathrm{Yb}$ excited state, with $\mathrm{Yb}_{5} T b_{4} \mathrm{D}_{\llcorner n}: \mathrm{D}_{\mathrm{S}}: \mathrm{D}_{\mathrm{L}}$ displaying the longest lifetime of $41 \mu \mathrm{s}$ (cf. $20 \mu \mathrm{s}$ for $\left.T b_{4} \mathrm{Yb}_{5} \mathrm{D}_{\mathrm{Ln}}: \mathrm{D}_{\mathrm{S}}: \mathrm{H}_{\mathrm{L}}\right)$. The Tb lifetime and quantum yields remain largely unperturbed within complexes containing proteo or deuterated Acac ligands with much smaller propensity of non-radiative multi-phonon quenching of $\mathrm{Tb}$ vs. $\mathrm{Yb}$ excited states (viz. substitution of $\mathrm{CH}$ for $\mathrm{CD}$ in $\left.D_{\llcorner n}: D_{S}: D_{L}\right) .{ }^{\left[{ }^{[6]}\right.}$ Sensitisation efficiencies in the range of $10-28 \%$ were obtain upon ligand irradiation. The radiative lifetimes of $\mathrm{Yb}$ were calculated ${ }^{[21]}$ varying from 665 to $900 \mu \mathrm{s}$.

The upconversion properties of the hetero-nonanuclear $\mathrm{Yb} / \mathrm{Tb}$ clusters were subsequently studied in $\mathrm{CD}_{3} \mathrm{OD}$ (Table 1). Irradiation of the ${ }^{2} \mathrm{~F}_{5 / 2} \leftarrow{ }^{2} \mathrm{~F}_{7 / 2} \mathrm{Yb}$ absorption band $\left(\lambda_{\text {exc }}=980 \mathrm{~nm}\right)$ gave rise to signals in the visible region, with the characteristic digitated visible emission of $\mathrm{Tb}\left({ }^{5} \mathrm{D}_{4} \rightarrow{ }^{7} \mathrm{~F}_{j}\right.$ with $J=6$ to 3 ) with a maximum at $545 \mathrm{~nm}$ (Fig. 3e, S36a-39a). The two photon behaviour of the UC emission was confirmed using Log/Log plots, whereby the intensity was found to have a quadratic dependence on the intensity of the incident light (Fig. 3f, S36b-39b). The slopes of the Log/Log plots were similar across the series and found to be in the range of $1.63-1.87$, pointing to the same mechanistic origins across all complexes - two excited ytterbium donors cooperatively sensitising one terbium acceptor, via the upconverted quasi-virtual $\mathrm{Yb}_{2}{ }^{* *}$ excited state. Inspection of the UC quantum yield across the series of complexes reveals that two factors affect the efficiency of these systems. First, is the variation of the donor-acceptor ratio. The UCQY of the $D_{L n}: D_{S}: H_{L}$ complexes increase with substitution of $\mathrm{Yb}$ for $\mathrm{Tb}$, giving an UCQY of $1.0 \times 10^{-7}$ for $\mathrm{Tb}_{1} \mathrm{Yb}_{8} \mathrm{D}_{\llcorner\mathrm{Ln}}: \mathrm{D}_{\mathrm{S}}: \mathrm{H}_{\mathrm{L}}$ which increases over tenfold for $\mathrm{Tb}_{4} \mathrm{Yb}_{5}$ to $1.1 \times 10^{-6}$. This is also borne out for the fully deuterated $\mathrm{D}_{\mathrm{Ln}}: \mathrm{D}_{\mathrm{S}}: \mathrm{D}_{\mathrm{L}}$ systems (cf. $6.0 \times 10^{-7}$ for $\mathrm{Tb}_{1} \mathrm{Yb}_{8}$ vs. $2.8 \times$ $10^{-6}$ for $\mathrm{Tb}_{4} \mathrm{Yb}_{5}$ ), conclusively demonstrating that having a large number of donor atoms does not produce the most efficient systems. Instead, $a \mathrm{Yb} / \mathrm{Tb} \approx 1$ gives the largest quantum yield in this class of complexes. ${ }^{[10 d, 11 a]}$ This is likely due to the presence of a higher local concentration of $\mathrm{Tb}$ acceptors in the $\mathrm{Tb}_{3} \mathrm{Yb}_{6}$ and $\mathrm{Tb}_{4} \mathrm{Yb}_{5}$ complexes, coupled with the fact that $\mathrm{Tb} \rightarrow \mathrm{Yb}$ energy transfer acts as a deactivation pathway for the Tb excited state, whereby more ytterbium atoms have a deleterious effect on the UCQY. The second factor affecting the efficiency of the UC emission is the level of deuteration of the complexes. It can be clearly seen that there is a significant increase in the UCQY for the fully deuterated $\left(D_{\llcorner n}: D_{S}: D_{L}\right)$ systems in comparison to the partially deuterated $\left(D_{\llcorner n}: D_{S}: H_{L}\right)$ congeners. For example, the efficiency is increased in the $\mathrm{Tb}_{1} \mathrm{Yb}_{8}$ complexes from $1.0 \times 10^{-7}$ to $6.0 \times 10^{-7}$ when substituting Acac for Acac- $d_{8}$. 

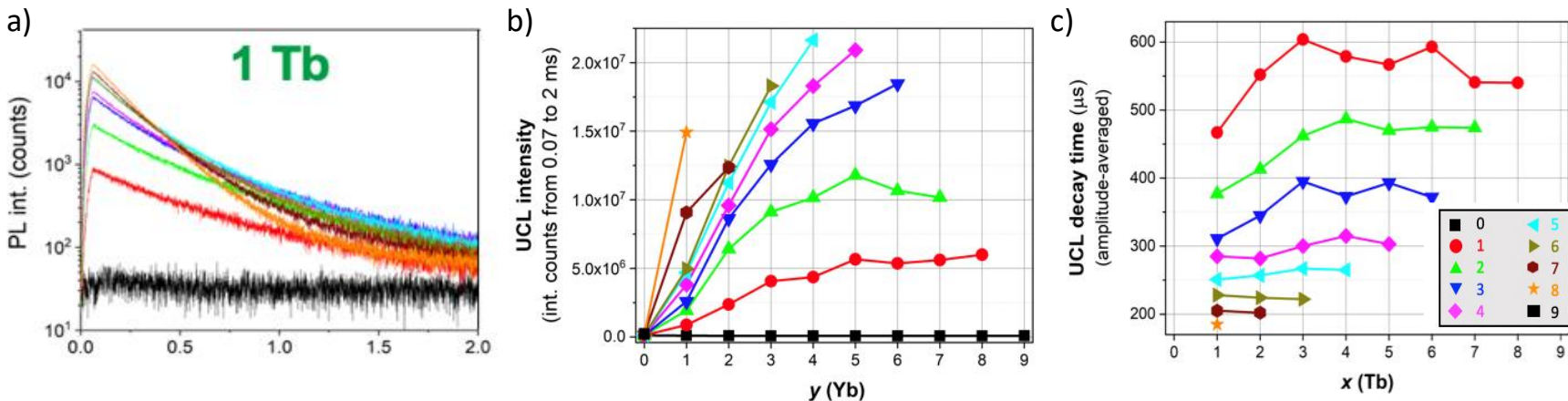

Figure $4 \mathrm{~A}$ ) Temporal emission profile of the $\left[\mathrm{TbYb}_{\mathrm{y}} \mathrm{Y}_{\mathrm{z}}(\mathrm{acac})_{16}(\mathrm{OD})_{10}\right]^{+}(\mathrm{y}+\mathrm{z}=8)$ complexes in $\mathrm{CD}_{3} \mathrm{OD}\left(\lambda_{\text {exc }}=980 \mathrm{~nm}\right.$, excitation for $60 \mu \mathrm{s}$, the color code for the value of $y$ is given in Fig. 4c). B) CL UC intensities of $\left[\mathrm{Tb}_{\mathrm{x}} \mathrm{Yb}_{\mathrm{y}} \mathrm{Y}_{\mathrm{z}}(\mathrm{acac})_{16}(\mathrm{OD})_{10}\right]^{+}(\mathrm{x}+\mathrm{y}+\mathrm{z}=9)$ complexes in $\mathrm{CD}_{3} \mathrm{OD}$ as a function of increasing $\mathrm{y} \mathrm{Yb}$ proportion (the color code for $x$ is given in the inset of Fig. 4c). C) Amplitude-averaged decay times of $\left[\mathrm{Tb}_{x} \mathrm{Yb}_{\mathrm{y}} \mathrm{Y}_{\mathrm{z}}(\mathrm{acac})_{16}(\mathrm{OD})_{10}\right]^{+}(\mathrm{x}+\mathrm{y}+\mathrm{z}=9)$ in $\mathrm{CD}{ }_{3} \mathrm{OD}$ as a function of the $x \mathrm{~Tb}$ proportion (the color code for $y$ is given in the inset.

This behaviour is mirrored by the other complexes and can be rationalised in the decreased probability of multi-phonon quenching of $\mathrm{Yb}$ by ligand $\mathrm{CD}$ oscillators compared to $\mathrm{CH}$ oscillators. In general, the trend is an approximately threefold increase in the UCQY efficiency in the fully deuterated systems. Inspection of these UCQY values against $T_{Y b}$ of conventional downshifted photoluminescence spectra $\left(\lambda_{e x c}=290 \mathrm{~nm}\right)$ shows a strong correlation; the lifetime of ytterbium is increased from ca. $17 \mu \mathrm{s}$ in the ( $\left.D_{\mathrm{Ln}}: \mathrm{D}_{\mathrm{S}}: \mathrm{H}_{\mathrm{L}}\right)$ complexes to $>40 \mu \mathrm{s}$ for the best performing $T b_{4} Y b_{5}\left(D_{L n}: D_{S}: D_{L}\right)$ complex. This is as expected, as a longer $T_{Y b}$ increases the probability of reaching the doubly excited state capable of CS of the Tb excited state, with a concomitant increase in the UCQY.

To further investigate the CSUC of the nonanuclear complexes and the possibility and efficiency of cooperative sensitisation, we prepared a combinatorial library of complexes with different molar fractions of $\mathrm{Tb}, \mathrm{Yb}$, and $\mathrm{Y}$ ions. The $\mathrm{Y}$ ions play the role of a spectroscopically silent Ln surrogate, being considered as chemically equivalent to $\mathrm{Ln}$ atoms of the second part of the $\mathrm{Ln}$ series with a similar ionic radius, ${ }^{[28]}$ and allowing to investigate the possible effect of self-quenching of $\mathrm{Yb}$ and $\mathrm{Tb}$ cations. With nine places to be occupied by one of the lanthanide ions, the complex can contain 55 different compositions of $\mathrm{Ln}$ ions $\left(\left[\mathrm{Tb}_{\mathrm{x}} \mathrm{Yb}_{\mathrm{y}} \mathrm{Y}_{\mathrm{z}} \mathrm{L}_{16}(\mathrm{OD})_{10}\right](\mathrm{OD})\right.$ with $x, y$ and $z$ integers and $x+y+z=$ 9 ) and therefore, we prepared 55 different samples by mixing $x / 9$ $\mathrm{TbCl}_{3} .6 \mathrm{D}_{2} \mathrm{O}, y / 9 \mathrm{YbCl}_{3} .6 \mathrm{D}_{2} \mathrm{O}, z / 9 \mathrm{YCl}_{3} .6 \mathrm{D}_{2} \mathrm{O}, \mathrm{Et}_{3} \mathrm{~N}$, and Acac in the proportions used for the synthesis. We subsequently measured their UCL decay kinetics at the ${ }^{5} \mathrm{D}_{4} \rightarrow{ }^{7} \mathrm{~F}_{5} \mathrm{~Tb}$ transition $(542 \pm 10 \mathrm{~nm})$ upon excitation of the ${ }^{2} \mathrm{~F}_{5 / 2} \leftarrow^{2} \mathrm{~F}_{7 / 2} \mathrm{Yb}$ transition (980 $\mathrm{nm}$ ) on a time-resolved fluorescence plate reader system (Fig. 4a, S40 and Table S41).

As expected, complexes without $\mathrm{Tb}$ or $\mathrm{Yb}$ did not show UCL at $542 \mathrm{~nm}$. All other mixtures showed significant UCL, including the ones that contained only $1 / 9$ of $\mathrm{Yb}$. Although a single $\mathrm{Yb}$ is not expected to sensitise $\mathrm{Tb}$, the statistical distribution of the three lanthanide ions results in a distribution of complexes with different amounts of $\mathrm{Tb}, \mathrm{Yb}$, and $\mathrm{Y}$, resulting, for $y=1$ in more than $26 \%$ of complexes with $y>1$ (see Supporting Information, Section S2 for discussion of the lanthanide ion distributions inside the complexes). The UCL decay curves clearly show that both UCL intensities (Fig. 4b) and decay times (Fig. 4c) are dependent on both $x$ and $y$.

Despite the distribution of complexes, it could have been expected that the UCL intensity increases with the amount of $\mathrm{Yb}$ ions because the probability of sensitising $\mathrm{Tb}$ acceptors increases with the number of surrounding $\mathrm{Yb}$ donors. ${ }^{[1 \mathrm{a}, 11 b]}$ However, the UCL intensities (Fig. 4a, 4b) clearly increased with both the number of $\mathrm{Yb}$ and $\mathrm{Tb}$ ions and were highest for similar amounts of $\mathrm{Yb}$ and $\mathrm{Tb}$ (maxima for $3<x<6$ and $6>y>3, z=0$ ), which means that both equally influenced the UCL intensity. When normalising the distribution of complexes with $x$ and $y$, one can also find that the highest intensities can be expected for $x$ and $y$ values between 3 and 6 (see Supporting Information, Section S5 and Fig. S42-S47 for discussion of the distributions).

Because luminescence decay times are concentrationindependent, they can provide further insight into the influence of $\mathrm{Tb}$ and $\mathrm{Yb}$ on the UCL of the different nonanuclear complexes. All decay curves (after the $60 \mu$ s excitation pulse) were fitted with a bi-exponential decay function (two different emitting Tb species). The full set of data is presented in Table S41, while Fig. 4b, 4c display the amplitude-averaged UC decay times as a function of $y$ and $x$. A general trend is that the higher the amount of $\mathrm{Yb}$, the more important is the short decay component and the shorter the average decay time. Despite the statistical distribution of the actual number of ions for each molar proportion $(x, y$, and $z)$, the UCL decay curves clearly show the transition from one single species (with a long lived mono-exponential UCL decay) for one $\mathrm{Yb}$ to another single species (emitting one short lived monoexponential UCL decay) for $8 \mathrm{Yb}$. All other samples ( $y=2$ to 7 ) show a double-exponential decay composed of both the long and short components. The decreasing Tb decay time with increasing $\mathrm{Yb}$ amount can be the result of an increased probability of Tb-to$\mathrm{Yb}$ energy transfer associated to an increase of non-radiative energy pathways. Another trend is that the average Tb decay time is approximately independent of Tb (x) (Fig. 4c) for $x$ and $y \geq 2$. The $x$-independent decay time for each $y$ means that the presence of $Y$ atoms does not influence the UC efficiency and that quenching by non-radiative energy losses associated to intramolecular Tb-to-Tb energy transfer, as often invoked in doped solids, ${ }^{[29]}$ does not occur. The detailed UCL decay analysis of the entire library of $55 \mathrm{~Tb}-\mathrm{Yb}-\mathrm{Y}$ nonanuclear complexes within a single microplate fluorescence experiment revealed that the UCL intensity is equally dependent on the number of $\mathrm{Tb}$ and $\mathrm{Yb}$ ions. Furthermore, the efficiency of sensitising a Tb acceptor by two $\mathrm{Yb}$ donors can be tuned via $y$ (the amount of $\mathrm{Yb}$ ). Notably, such experiments were only possible due to the outstanding molecular UCL brightness of the nonanuclear $\mathrm{Yb}-\mathrm{Tb}-\mathrm{Y}$ complexes and their very simple preparation and good stability over a few hours after preparation.

\section{Conclusion}

We have prepared a coherent series of homo- and heterononanuclear complexes and investigated their solution-state properties. The diamagnetic yttrium complex was probed by NMR 
spectroscopy and computational investigations, revealing that the complex retains its solid-state structure and symmetry in solution. Low temperature experiments expose the prevalence of diasteromeric and enantiomeric pairs $((\Delta, \Lambda),(\Delta, \Delta),(\Delta, \Lambda),(\Delta, \Lambda))$ in the slow-exchange regime, corresponding to low-symmetry complexes. Studies of the upconversion properties of the $\mathrm{Yb}_{9}$ cluster in $\mathrm{CD}_{3} \mathrm{OD}$ gave rise to an emission band at $503 \mathrm{~nm}$ upon irradiation of $980 \mathrm{~nm}$, corresponding to the cooperative luminescence upconversion, the first time such a phenomenon has been observed in solution. The hetero-nonanuclear complexes $\mathrm{Tb}_{\mathrm{x}} \mathrm{Yb}_{\mathrm{y}}$ exhibited cooperative sensitisation upconversion arising from energy transfer from a doubly excited state of $\mathrm{Yb}$ to sensitise $\mathrm{Tb}$. The study of a library of complexes with varying donor-acceptor ratios concludes that the most efficient systems are those containing an average ratio close to one. These results coupled with the use of highly deuterated complexes demonstrated that the $\mathrm{Yb}_{5} \mathrm{~Tb}_{4}\left(\mathrm{D}_{\llcorner\mathrm{n}}: \mathrm{D}_{\mathrm{S}}: \mathrm{D}_{\mathrm{L}}\right)$ compound presents the most efficient molecular UC in solution to date.

\section{Acknowledgements}

Financial support is gratefully acknowledged (L.J.C. and R.C.K.) from the French Ministère de l'Education Nationale et de la Recherche, the French Canada Research Fund (KS), Frontier Research in Chemistry Foundation (LabEx CSC, ANR-10-LABX0026 CSC), and the French National research agency (LAPIN project $n^{\circ}$ ANR-20-CE09-0021-02; LUCAS project n'ANR-19CE29-0014-01) for financial support. N.H thanks the European Commission (Horizon 2020 - MSCA-IF for L.F.-S.). Dr Bruno Vincent is acknowledged for technical support for NMR. A. R.-R. and C. P.-I. thank Centro de Computación de Galicia (CESGA) for providing the computer facilities and the Ministerio de Ciencia e Innovación (Grant PID2019-104626GB-I00).

[1] a) F. Auzel, Chem. Rev. 2004, 104, 139-173.; b) D. R. Gamelin, H. U. Güdel, Acc. Chem. Res. 2000, 33, 235-242.

[2] a) G. Chen, H. Qiu, P. N. Prasad, X. Chen, Chem. Rev. 2014, 114, 5161-5214.; b) C. Duan, L. Liang, L. Li, R. Zhang, Z. P. Xu, J. Mater Chem. B, 2018, 6, 192-209.; c) S. Wen, J. Zhou, K. Zheng, A. Bednarkiewicz, X. Liu, D. Jin, Nat. Commun. 2018, 9 (1), 2415.

[3] a) B. Zhou, L. Yan, J. Huang, X. Liu, L. Tao, Q. Zhang, Nat. Photonics 2020, 14 (12), 760-766.; b) B. Tian, A. Fernandez-Bravo, H Najafiaghdam, N. A. Torquato, M. V. P. Altoe, A. Teitelboim, C. A. Tajon, Y. Tian, N. J. Borys, E. S. Barnard, M. Anwar, E. M. Chan, P. J. Schuck, B. E. Cohen, Nat. Commun. 2018, 9 (1), 3082

[4] a) C. Lee, E. Z. Xu, Y. Liu, A. Teitelboim, K. Yao, A. Fernandez-Bravo, A. M. Kotulska, S. H. Nam, Y. D. Suh, A. Bednarkiewicz, B. E. Cohen, E. M. Chan, P. J. Schuck, Nature 2021, 589 (7841), 230-235.; b) B. Zhou, B. Tang, C. Zhang, C. Qin, Z. Gu, Y. Ma, T. Zhai, J. Yao, Nat. Commun 2020, 11 (1), 1174.; c) F. Wang, R. Deng, J. Wang, Q. Wang, Y. Han, H. Zhu, X. Chen, X. Liu, Nat. Mater. 2011, 10 (12), 968-973.; d) Y. Wu, J. Xu, X. Qin, J. Xu, X. Liu, Nat. Commun. 2021, 12 (1), 2022.

[5] A. Domínguez, B. Suarez-Merino, F. Cerio, J. Nanosci. Nanotechnol. 2014, 14, 766-779.; b) D. Bobo, K. J. Robinson, J. Islam, Pharm. Res. 2016, 33 (10), 2373-2387.

[6] A. Beeby, I. M. Clarkson, R. S. Dickins, S. Faulkner, D. Parker, L. Royle, A. S. de Sousa, J. A. G. Williams, M. Woods, J. Chem. Soc., Perkin Trans. 21999, No. 3, 493-504.

[7] M. Haase, H. Schäfer, Angew. Chem. Int. Ed. 2011, 50, 5808-5829.

[8] a) A. M. Nonat, L. J. Charbonnière, Coord. Chem. Rev. 2020, 409, 213192.; b) W. D. Horrocks, D. R. Sudnick, J. Am. Chem. Soc. 1979, 101 (2), 334-340.

[9] a) J. Kalmbach, C. Wang, Y. You, C. Förster, H. Schubert, K. Heinze, U. Resch-Genger, M. Seitz, Angew. Chem. Int. Ed. 2020, 59, 18804-18808.; b) J. T. Mo, Z. Wang, P. Y. Fu, L. Y. Zhang, Y. N. Fan, M. Pan, C. Y. Su, cCS Chem. 2020, 2, 729-738.
[10] a) B. Golesorkhi, H. Nozary, A. Fürstenberg, C. Piguet, Mater. Horiz., 2020, 7, 1279-1296.; b) L. J. Charbonnière, Dalton Trans. 2018, 47 (26) 8566-8570.; c) B. Golesorkhi, A. Fürstenberg, H. Nozary, C. Piguet, Chem. Sci., 2019, 10, 6876-6885.; d) A. Nonat, S. Bahamyirou, A Lecointre, F. Przybilla, Y. Mély, C. Platas-Iglesias, F. Camerel, O. Jeannin, L. J. Charbonnière, J. Am. Chem. Soc. 2019, 141, 1568-1576.

[11] a) B. Golesorkhi, H. Nozary, L. Guénée, A. Fürstenberg, C. Piguet, Angew. Chem. Int. Ed. 2018, 57, 15172-15176.; b) A. Nonat, C. F. Chan, T. Liu, C. Platas-Iglesias, K.-L. Wong, L. J. Charbonnière, Nat. Commun., 2016, 7:11978.

[12] a) N. Souri, P. Tian, C. Platas-Iglesias, K.-L. Wong, A. Nonat, L. J. Charbonnière, J. Am. Chem. Soc. 2017, 139, 1456-1459.; b) R. C Knighton, L. K. Soro, A. Lecointre, G. Pilet, A. Fateeva, L. Pontille, N. Hildebrandt, L. Francés-Soriano, L. J. Charbonnière, Chem. Commun. 2021, 57, 53-56.

[13] I. Roy, A. Garci, Y. Beldjoudi, R. M. Young, D. J. Pe, M. T. Nguyen, P .J. Das, M. R. Wasielewski, J. F. Stoddart, J. Am. Chem. Soc. 2020, 39, 16600-13609.

[14] F. Auzel, D. Meichenin, F. Pellé, P. Goldner, Opt. Mater., 1994, 4(1), 3541.

[15] D. A. Gálico, J. S. Ovens, F. A. Sigoli, M. Murugesu, ACS Nano 2021, 15 (3), 5580-5585.

[16] D. Guettas, C. M. Balogh, C. Sonneville, Y. Malicet, F. Lepoivre, E. Onal, A. Fateeva, C. Reber, D. Luneau, O. Maury, G. Pilet, Eur. J. Inorg. Chem. 2016, 3932-3938.

[17] D. H. Moseley, S. E. Stavretis, K. Thirunavukkuarasu, M. Ozerov, Y. Cheng, L. L. Daemen, J. Ludwig, Z. Lu, D. Smirnov, C. M. Brown, A Pandey, A. J. Ramirez-Cuesta, A. C. Lamb, M. Atanasov, E. Bill, F. Neese, Z.-L. Xue, Nat. Commun. 2018, 9 (1), 2572.

[18] S. Petit, F. Baril-Robert, G. Pilet, C. Reber, D. Luneau, J. Chem. Soc. Dalt. Trans. 2009, No. 34, 6809-6815.

[19] For the sake of simplicity only the $(\Delta, \Lambda)$ and $(\Delta, \Delta)$ structures were calculated.

[20] G. D. R. Napier, J. D. Neilson, T. M. Shepherd, Chem. Phys. Lett. 1975, 31 (2), 328-330.

[21] M. H. V. Werts, R. T. F. Jukes, J. W. Verhoeven, Phys. Chem. Chem. Phys. 2002, 4, 1542-1548.

[22] R. C. Benson, H. A. Kues, Phys. Med. Biol. 1978, 23 (1), 159-163.

[23] J. Olmsted, J. Phys. Chem. 1979, 83 (20), 2581-2584.

[24] N. Weibel, L. C. Charbonnière, M. Guardigli, A. Roda, R. Ziessel, J. Am. Chem. Soc. 2004, 126, 4888-4896.

[25] a) E. Nakazawa, S. Shionoya, Phys. Rev. Lett. 1970, 25, 1710-1712.; b) W. P. Qin, Z.-Y. Liu, C.-N. Sin, C.-F. Wu, G.-S. Qin, Z. Chen, K.-Z. Zheng, Light Sci. Appl. 2014, 3, 1-6.

[26] L. Zhang, J. Yang, Z. Zhang, H. Yu, W. Pan, Ceram. Int. 2019, 45, 92789282.

[27] J.-C. G. Bünzli, Chem. Rev. 2010, 110 (5), 2729-2755

[28] R. D. Shannon, Acta Cryst, 1976, A32, 752-767.

[29] a) F. Auzel, G. Baldacchini, L. Laversenne, G. Boulon, Opt. Mater. 2003 24, 103-109.; b) F. Auzel, J. Lumin. 2002, 100, 125-130 